\title{
¿CÓMO SER NEGRO EN UN MUNDO SIN NEGROS? CATEGORÍAS RACIALES E IDENTIDADES POLÍTICAS ENTRE AFRODESCENDIENTES DE LA CIUDAD DE SANTA FE (ARGENTINA)
}

\author{
COMO SER NEGRO NUM MUNDO SEM NEGROS? CATEGORIAS \\ RACIAIS E IDENTIDADES POLÍTICAS ENTRE AFRODESCENDENTES \\ DA CIDADE DE SANTA FÉ (ARGENTINA)
}

\author{
Francisco Sosa \\ Universidad Nacional del Litoral - UNL
}

\section{Resumen}

En el presente trabajo analizamos el modo en que un grupo de mujeres santafesinas, articulando identidades políticas globales y categorías raciales locales, construyen una identidad afrodescendiente en la actualidad. Teniendo en cuenta el proceso de invisibilización social al que han sido sometidos los afroargentinos en nuestro país desde finales del siglo XIX, indagamos en el potencial contradiscursivo que supone identificarse como "negro" de Argentina. Por otro lado, atendemos a sus experiencias de vida, advirtiendo los múltiples sentidos que acarrea la portación de identidades racializadas, y las complejas imbricaciones con una forma de negritud asociada a una "forma de ser" propia de las clases populares argentinas.

Palabras claves: Afrodescendientes. Raza. Identidades Políticas. Santa Fe.

\section{Resumo}

Este artigo analisa o modo em que um grupo de mulheres santafesinas, articulando identidades políticas globais e categorias raciais locais, constroem uma identidade afrodescendente na atualidade. Tendo em conta o processo de invisibilização social ao que foram submetidos os afroargentinos em nosso país desde finais do século XIX, indagamos no potencial contra discursivo que supõe identificar-se como "negro" de Argentina. Por outro lado, atendemos às suas experiências de vida, advertindo os múltiplos sentidos que traz o fato de portar uma identidade racializada, e as complexas imbricações com uma forma 
de negritude associada a uma "forma de ser" própria das classes populares argentinas.

Palavras chaves: Afrodescendentes. Raça. Identidades Politicas. Santa Fe.

\section{Introducción}

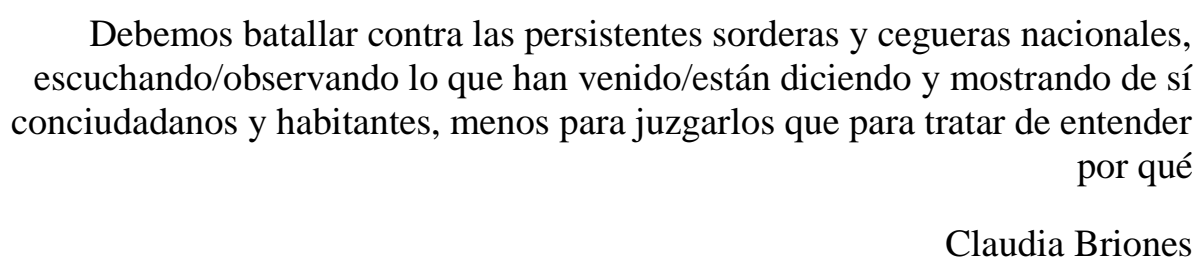

La presencia de afrodescendientes en la región del Litoral es un continuo que se inicia antes de la conformación del Estado Nacional. Desde el siglo XVI, y principalmente durante los siglos XVIII y XIX, millones de africanos fueron trasladados a América para ser utilizados como mano de obra esclava por parte de los europeos que residían en el continente. Sin embargo, en nuestro país, el ideal de nación se construyó a partir del señalamiento de la blanquedad - atributo de europeidad - de sus ciudadanos. Para ello, entre otros "mitos", se debió sancionar la casi inexistencia de esclavos en la región y la pronta desaparición de sus descendientes.

Recuperando los conceptos propuestos por Briones (2005) y Geler (2016), sostenemos que la "desaparición” de los negros y negras debe entenderse como un complejo proceso de erosión de una alteridad interna racializada, proceso en el cual el discurso dominante de nación ha desempeñado un rol fundamental - acompañado de políticas concretas de invisibilización, como aquellas llevadas a cabo a través de los censos de población y la educación formal normalizadora. Este discurso, en tanto "sistema social de referencias semióticas"i (RAITER Y ZULLO, 1999), ha establecido que en Argentina lo "normal” es lo blanco, configurando la blanquitud como una bolsa clasificatoria amplia basada en la percepción visual que incorpora todo lo que no entra en la estrechez de lo negro racial, resumido en unas características muy limitadas y específicas (GELER, 2016, p. 74). A partir de este sistema binomial, a través del cual percibimos racialmente a los otros, toda persona negra es necesariamente situada en la lejanía (temporal o geográfica). 
SANTA FE (ARGENTINA)

En oposición a estas representaciones características de la "formación nacional de alteridad" argentina ${ }^{\mathrm{ii}}$, a partir de la década de 1980 asistimos a un proceso paulatino de reivindicaciones identitarias, tanto de comunidades indígenas como del colectivo afrodescendiente, que configuran una serie de relatos alternativos a ese discurso dominante. Estos procesos han contribuido a colocar en la agenda del Estado y de los medios de comunicación una problemática que parecía superada: la cuestión racial.

Teniendo en cuenta estos aspectos, en este trabajo nos centramos en las experiencias de Lucía, Mirta y Maríaii, un grupo de mujeres descendientes de esclavizados de origen africano de la ciudad de Santa Fe (Argentina) ${ }^{\text {iv }}$. De modo particular, atendemos a las estrategias desplegadas por estas mujeres para construir una identidad afrodescendiente en una sociedad atravesada por una narrativa de nación que históricamente enfatizó la blanquedad de sus ciudadanos. A su vez, exponemos parte de sus trayectorias de vida, evidenciando los múltiples sentidos que acarrea la portación de identidades racializadas, y las complejas conexiones con la dimensión de clase.

En el primer apartado indagamos en el proceso de invisibilización social de los afroargentinos, poniendo en evidencia la existencia de líneas de continuidad que nos remontan desde el orden colonial hasta el presente. En el segundo apartado damos cuenta del activismo afrosantafesino, abordando las estrategias de construcción de una identidad afrodescendiente y sus implicancias contra-discursivas. En el tercer apartado, recuperamos experiencias vividas por Lucía, Mirta y María, que nos exponen la pervivencia de mecanismos subrepticios de discriminación racial en nuestro país y tejen múltiples y contradictorias relaciones con una forma de negritud asociada a una "forma de ser" propia de las clases populares. Por último, volvemos sobre los principales tópicos analizados en el trabajo y presentamos una serie de conclusiones con el objetivo de abrir futuras vías de indagación.

\section{La "blanquedad" de los argentinos como narrativa dominante de nación}

En América Latina, a lo largo del siglo XIX, la conformación de los Estados nacionales fue acompañada de la creación de "grandes relatos" de nación ${ }^{\mathrm{v}}$. En nuestro país, las elites decimonónicas forjaron un ideal de nación eminentemente blanco: el modo de representar pertenencia al Estado-Nación se proyectó a través del “crisol de razas"vi , formado por una mezcla de muchos segmentos blancos europeos ${ }^{\mathrm{vii}}$ (RIBEIRO, 2002). 
Este ideal de nación pasó a formar parte del sentido común de sus ciudadanos imponiéndose la idea según la cual "los argentinos descendemos de los barcos". Como afirma Briones (2005), tal aseveración supone un doble juego: a la par de trazar distancias nítidas respecto de ciertos "otros externos" (los "aindiados hermanos" de ciertos países latinoamericanos), se secuestra y silencia internamente la existencia de otro tipo de alteridades, como la de los pueblos indígenas y también la de los afrodescendientes, pues las poblaciones asociadas a un remoto pasado africano ligado a la esclavitud no encuentran cabida alguna en un "venir de los barcos" que parece acotarse a los siglos XIX y XX.

Al mismo tiempo, junto al "crisol de razas" explícito, el que contribuyó a europeizar a los argentinos, argentinizando a los inmigrantes europeos, existe un "crisol" encubierto que ha conducido a convertir en connacionales - aunque de tipo particular - a los conciudadanos que no podían ser ni extranjerizados, ni eyectados de los contornos geo-simbólicos de la nación, ni alterizados en un sentido fuerte (BRIONES, 2005). Es este último el que produce los "negros", un espacio simbólico de reunión/fusión tanto de indígenas y afrodescendientes, como de sectores populares del interior e inmigrantes indeseables. Como afirma Rufer (2013), en Argentina, el negro es el resto: los que de modo general quedaron dentro del crisol de razas en una especie de destilado del que nunca se habla más que en términos de clase y trabajo.

Entonces, el argentino es indistintamente blanco, operando como forma de identidad naturalizada y, por lo tanto, como paradigma desde el cual se marca lo distinto, lo anormal. Esto configura otra importante representación social sobre la argentinidad, aquella que afirma que "en Argentina no habría negros-negros" - en todo caso hay "cabecitas negras", "villeros", "grasas", o simplemente "negros", aunque de "alma", nunca de "raza". Identificar un sujeto como "negro" no supone asignarlo a una comunidad percibida como diferente, por el contrario, este marcador "racial" define una posición de clase.

En este sentido, compartimos el análisis propuesto por Geler (2007), quien sugiere que la población afroargentina pasó por un proceso de etnicización ${ }^{\text {viii }}$. Para la autora, los prohombres de la nación enmarcaron a los negros y mulatos argentinos dentro de la comunidad nacional, posibilitando el despojo de identidades/marcaciones no deseadas, pero promoviendo también la aceptación de una fuerte jerarquización racial en la sociedad donde lo blanco se reconoció unánimemente como lo mejor: la negritud argentina era buena porque 
¿CÓMO SER NEGRO EN UN MUNDO SIN NEGROS? CATEGORÍAS RACIALES E IDENTIDADES POLÍTICAS ENTRE AFRODESCENDIENTES DE LA CIUDAD DE SANTA FE (ARGENTINA)

permitía el pasaje, no porque fuera buena en sí misma (GELER, 2007, p. 149). Guiados por las ideas de "progreso" asociadas a la europeidad, y las teorías de superioridad racial en boga, las elites decimonónicas promovieron el pasaje de los afroargentinos al cuerpo nacional bajo la condición de su des-marcación. En este asunto, las mismas elites afroargentinas desempeñaron un rol fundamental.

\section{La identidad afro-argentina como contra-discurso}

La narrativa dominante de nación que históricamente enfatizó la blanquedad de los argentinos ha comenzado a resquebrajarse en las últimas décadas. En efecto, a partir de la década de 1980 se inaugura un proceso paulatino de reivindicación de identidades étnicas y promoción de sus culturas, favorecido por el desarrollo de una narrativa multicultural a nivel local que habilita ámbitos de expresión para la presencia simbólica de estas minorías.

La re-emergencia étnica responde también a un contexto internacional atravesado por un proceso de transnacionalización de la temática de las minorías, esto es, la integración en las agendas de organizaciones internacionales y agencias multilaterales, tales como el Banco Mundial, el Banco Interamericano de Desarrollo, la ONU, la OIT, etc. (GARCÍA, 2001; LÓPEZ, 2005). Favorecidos por esta "estructura de oportunidades políticas" (FRIGERIO Y LAMBORGHINI, 2011), el 21 de marzo (Día Internacional de la Lucha contra la Discriminación Racial) de 1988, Lucía Molina junto con su marido Mario López fundan la Casa de la Cultura Indo-Afro-Americana en la ciudad de Santa Fe.

Con su nombre, los fundadores pretenden enfatizar las "tres raíces" americanas, indicando que además de los europeos, en el continente hubo - y actualmente hay - presencia indígena y afrodescendiente. Tiene como principales objetivos:

(...) el rescate, la defensa, el desarrollo, la difusión y la valoración de las prácticas culturales provenientes de los pueblos originarios y de los africanos trasplantados a América por la esclavitud y la lucha contra el racismo y todo tipo de discriminación; trabajar a nivel local, nacional, regional e internacional con organizaciones afines $y$ establecer un nivel de coordinación y difusión de la temática; promover el desarrollo de las comunidades y de las personas indo y afroamericanas y fomentar, defender y difundir la temática de los Derechos Humanos y de las minorías (CCIAA, 2014). 
La Casa está presidida por Lucía, mujer de alrededor de 70 años, quien se define como activista afroargentina del tronco colonial. A su vez, se encuentra conformada por personas interesadas en la temática afro, entre las que se destaca Mirta, mujer de aproximadamente 50 años, militante feminista y afrodescendiente. Actualmente, la institución funciona en la casa de Lucía, ubicada en el barrio Santa Rosa de Lima, uno de los tantos barrios periféricos de la ciudad de Santa Fe.

Desde sus inicios, los fundadores de la Casa logran articular una red de relaciones con distintas organizaciones y militantes por la causa afro-indígena. A partir de los años noventa, impulsados por la transnacionalización de las organizaciones de afrodescendientes en la región, la institución se orienta hacia el activismo político afroargentino de forma exclusiva. Con la llegada del nuevo milenio, el circuito transnacional se consolida, multiplicando los espacios en que los afrodescendientes actúan y, consecuentemente, circulan sus discursos, subrayando la reconfiguración de una identidad política afrodescendiente latino-americana distintiva, diferente de aquella de años anteriores.

Si bien la adopción de estas "identidades globales" posee un aspecto banalizador y achatador, en tanto responde a una agenda global más fiel a cuestiones nacionales internas de los países centrales que a problemáticas e idiomas políticos locales (SEGATO, 2007), sostenemos que también supone una serie de ventajas. En efecto, el surgimiento de estas identidades políticas habilita la configuración de solidaridades estables para la acción colectiva $^{\text {ix }}$. Dicho de otro modo, la principal contribución es "nombrar", esto es, "inscribir el sufrimiento común de sujetos que, aunque exhiben la misma marca racial, no son un grupo de cultura y se encuentran dispersos en la sociedad envolvente" (SEGATO, 2007, p. 28). Esto se presenta como un aspecto positivo en una sociedad cuya "ceguera cromática" nos ha conducido históricamente a imaginarnos blancos y europeos, desestimando la posibilidad de existencia de un orden racial (y racista) particular.

Atendiendo a estos procesos, las activistas afrosantafesinas nucleadas en la Casa despliegan una serie de estrategias que apelan, por un lado, al cuestionamiento del discurso dominante de nación que históricamente enfatizó la blanquedad de los argentinos y, por otro lado, a la reivindicación positiva de la negritud en nuestro país. Ello se advierte en los 
¿CÓMO SER NEGRO EN UN MUNDO SIN NEGROS? CATEGORÍAS RACIALES E IDENTIDADES POLÍTICAS ENTRE AFRODESCENDIENTES DE LA CIUDAD DE SANTA FE (ARGENTINA)

contenidos y temas abordados por Lucía y Mirta en sus discursos públicos, tanto como en las prácticas promovidas desde la institución.

En lo que respecta a sus discursos, se destaca la construcción de una narrativa común al colectivo afrodescendiente en Argentina. Tanto Lucía como Mirta aluden a mitos de origen y a figuras heroicas, enarbolando una historia de sus antepasados que comienza con el tráfico atlántico y se remonta hasta el presente. Esto es particularmente evidente en la poesía de Lucía:

Llegaron, porque los trajeron, de prepo nomás.

Arrancados de sus pagos, se afincaron como pudieron,

Se quedaron y siguieron, se callaron hasta mimetizarse.

Pero dicen que África sigue al negro a donde vaya, Mama África se rehace en cada célula

Y se reproduce para no morir.

Así, generaciones tras generaciones denotan su paso,

A pesar del blanqueamiento.

El silencio fue y se transformó en un grito ahogado,

Hasta que al librarse pueda decir:

Aquí nos trajeron, aquí nos quedamos,

Y ahora aquí estamos, luchando por nuestros derechos.

Con este poema, titulado "Ser afrodescendiente" (1998), la presidenta de la Casa introduce su artículo publicado en el libro "Argentina, raíces afro" (2014), así como sus exposiciones en la mesa redonda "El Federalismo de los Afroargentinos ayer y hoy" (2015), y en la charla realizada en la "7ma Feria de Organizaciones Sociales" (2016). Esta reiteración nos incita a pensar en que, de alguna forma, dicho poema actúa como "carta de presentación" de Lucía. El mismo traza una conexión directa entre los africanos esclavizados y los afrodescendientes en el presente. También indica una serie de factores que le dan cohesión al colectivo afro, mostrándolo como víctima de un proceso de explotación y negación que continúa en la actualidad.

Esta característica se encuentra también presente en el discurso de Mirta, quien durante la mesa redonda mencionada anteriormente alude a la "figura mítica" por excelencia de las organizaciones de afrodescendientes nucleadas en nuestro país:

Mirta: [las mujeres afrodescendientes] dejaron su impronta y sangre en esta sociedad (...) me gustaría hacer mención a un ejemplo, para nosotras las mujeres africanas y afrodescendientes: María Remedios del Valle, quien fue considerada la madre de la patria. 
Como observamos, el pasado afro ocupa un lugar central en el discurso de los miembros de la Casa. De hecho, si nos detenemos en el análisis de las palabras más utilizadas por Lucía y Mirta en los discursos a los que tuvimos acceso, la afirmación que más se repite es "nuestra historia", la cual se complementa con adjetivos como "rica" y "triste". Esta constatación nos conduce a sostener que, para las activistas nucleadas en la Casa, el principal objetivo radica en reconstruir una historia común, reivindicando la presencia negra en la región, mostrando sus riquezas y, al mismo tiempo, señalando las múltiples problemáticas a las que se han visto, y aún se ven, afectados.

Otro de los aspectos que resalta de la oratoria de las activistas afrosantafesinas se relaciona con la construcción de una cultura común. Tanto Lucía como Mirta destacan la existencia de prácticas culturales propias, supuestamente traídas desde África. Esto se refleja en otro poema escrito por Lucía:

Cuando tocamos un tambor, Se eleva nuestra alma, Hasta llegar muy lejos, Al encuentro de nuestros ancestros.

Cuando sentimos tocar un tambor, Nuestra sangre corre o mejor dicho galopa, Porque nuestro corazón se emociona.

Cuando escuchamos un tambor,

Lo sentimos...

Y todo nuestro cuerpo se mueve al compás.

Cuando tocamos,

Escuchamos,

Bailamos...

¡Ay! África mía,

Por qué te extraño tanto,

Pero qué orgullosa me siento...

De tener el color,

El color de tu tierra en mi piel.

En este poema, titulado "Tambores" (2014), su autora indaga en la conexión ancestral que supone para ella - en tanto parte de un colectivo mayor -, el toque del tambor. Al igual que en el primer poema analizado, Lucía muestra su preocupación por las raíces identitarias, remontándose a un origen común en África que se conecta con el presente. Lo que se destaca 
¿CÓMO SER NEGRO EN UN MUNDO SIN NEGROS? CATEGORÍAS RACIALES E IDENTIDADES POLÍTICAS ENTRE AFRODESCENDIENTES DE LA CIUDAD DE SANTA FE (ARGENTINA)

del poema son las múltiples aristas que posee dicha conexión. En efecto, para su autora, ésta se expresa físicamente en el "cuerpo" que "se mueve al compás", en la "sangre" que "corre o mejor dicho galopa", y en el "color" de la tierra africana en la piel. Pero también se advierte en el nivel de las emociones, porque el "corazón se emociona", y porque "África" se extraña y es motivo de orgullo. Sin embargo, no se trata solamente de una conexión con el pasado: para Lucía, al igual que para la mayoría de los activistas afrodescendientes en Argentina, los tambores simbolizan su cultura, aquello que los representa frente a la otredad: no es simplemente un canto o un baile, es su canto y es su baile.

De hecho, desde la institución se promueve la recreación de un candombe afrolitoraleño, conformado por toques que entremezclan ritmos del folklore litoraleño "criollo" (rasguido doble, chamarrita), ritmos de herencias africanas de la zona de Corrientes, como la charanda o zemba, y el estudio de culturas afroamericanas (BROGUET, 2017). A pesar de no tener un bagaje transmitido por generaciones precedentes, tanto Lucía como Mirta incorporan estas prácticas culturales asociadas a la población negra en Argentina como forma de visibilizar un reclamo fundamentalmente político.

Efectivamente, si en Argentina la sociedad nacional fue el resultado de lo que Segato (2007) ha llamado "terror étnico", del pánico a la diversidad, en un medio en el cual la vigilancia cultural pasó por mecanismos institucionales y por estrategias informales de vigilancia, la reivindicación de una identidad afro-argentina se erige como un poderoso discurso contra-hegemónico. La intención de construir un relato alternativo, que transforme la narrativa dominante vigente, se advierte en el modo en que Lucía y Mirta refieren a la presencia negra en la historia argentina:

Lucía: porque siempre nos han enseñado que a esa abuela negra y a esa abuela indígena [hay que] esconderla en el placard. Es hora de que nosotros la saquemos y que nos sintamos orgullosos de todas sus enseñanzas. Porque más allá que la tengamos escondida, las enseñanzas ancestrales son inherentes a todos nosotros.

Mirta: (...) las tetas de esas negras amamantaron al $90 \%$ de los que fueron después nuestros próceres argentinos (...) a pesar de todo lo hecho, ellas no existieron, y me refiero a las mujeres esclavizadas y afrodescendientes, no existieron para la historia oficial.

En estas citas observamos la utilización del nosotros “inclusivo", posicionándose ellas mismas como parte de un colectivo mayor - la nación Argentina -, el cual les otorga 
homogeneidad. Aquí radica el carácter político y estratégico de la construcción de una identidad afroargentina: no son sólo "negros en Argentina", son "negros de Argentina", y en tanto tales, exigen una reformulación de quiénes somos los argentinos.

\section{La marca racial}

A pesar de la "positividad en la alteridad" que hoy se vislumbra, es decir de la reemergencia de estas identidades en clave étnico-racial, es importante recordar que "raza es efecto y no causa" (SEGATO, 2007). En efecto, como afirma Restrepo (2012), las categorías raciales con las cuales nos pensamos a nosotros mismos y a los otros constituyen uno de los legados más presentes del colonialismo. Como tales, troquelan nuestros marcos interpretativos y comportamientos, abarcando planos disímiles que van desde los estéticos hasta el deseo y lo moral. No es, por lo tanto, de estos sujetos marcados racialmente que parte un deseo de diferencia o reconocimiento como valor, sino que se torna valor como contradiscurso después de la experiencia de rechazo.

Estas consideraciones son fundamentales dado que, de algún modo, dotan de sentido a la labor de los activistas afroargentinos. De hecho, la principal motivación para la conformación de la Casa de la Cultura Indo-Afro-Americana radica en la experiencia de vida de su propia fundadora: Lucía se había sentido rechazada desde su infancia por ser más "oscura" que los demás y había encontrado en la lucha por los derechos de los afroamericanos un lugar de empoderamiento. Como ella misma manifiesta:

Cuántas veces regresé a casa llorando, después me miraba al espejo y me decía "soy hermosa", era la época donde los afronorteamericanos decían que "lo negro era hermoso" y eso me daba fuerza para continuar al día siguiente (MOLINA, 2014, p. 57).

La identificación de Lucía con lo afro-americano también se daba en torno a las prácticas culturales. En efecto, ella afirma:

Siempre me refugié y me reconocí como hija del Brasil, será porque en esa época lo que conocíamos era que solo en Brasil había negros y yo me sentía identificada en su música, sus cantos, en fin, en todo, con el país hermano (MOLINA, 2014, p. 57). 
¿CÓMO SER NEGRO EN UN MUNDO SIN NEGROS? CATEGORÍAS RACIALES E IDENTIDADES POLÍTICAS ENTRE AFRODESCENDIENTES DE LA CIUDAD DE SANTA FE (ARGENTINA)

Sin embargo, en su entorno familiar, la herencia africana nunca había sido mencionada, a pesar de que su padre, Ignacio Molina, había formado parte de la Sociedad Coral Carnavalesca "Negros Santafesinos"x. La única referencia que Lucía poseía era la forma en que él le decía: "Mushinga", una palabra de origen afro que significa "morena linda"xi.

De ningún modo esto se trata de un caso aislado. La carga negativa asociada a las características físicas de los sujetos considerados "negros" en su entorno social, así como el silencio familiar en relación a estos temas, son un lugar común en los relatos de las mujeres afrosantafesinas. En efecto, en una entrevista realizada por Broguet (2017), Mirta decía "tengo la característica de ser en mi familia lo que se llama un salto pa atrás: venir de una familia de blancos y nacer con la piel oscura”. En otra ocasión manifestaría que en su casa nunca se había hablado acerca del tema y que, al igual que Lucía, el hecho de no conocer su propia historia fue motivo de padecimiento.

De modo similar, María manifiesta el silencio y el rechazo al relatar algunas experiencias vividas. En este punto, cabe realizar una aclaración: a diferencia de las activistas nucleadas en la Casa de la Cultura Indo-Afro-Americana, María pertenece a una familia de clase media y posee educación universitaria. A raíz de un programa de movilidad estudiantil tuvo la posibilidad de residir e investigar en Brasil. A pesar de no estar implicada en la militancia, se considera afrodescendiente, aunque aclara:

María: también me considero descendiente de otras cosas, porque de alguna manera soy una mezcla. Evidentemente sí, soy descendiente de negro, esclavo, colonial. Y también de indios, y también de otras cosas, pero bueno, es como saliente en el pelo, el color y los demás signos.

María sostiene que fueron fundamentalmente el psicoanálisis y su estancia en Brasil los motivos que le permitieron "valorar la parte negra", y tejer una historia de "muchas cosas sueltas", a las cuales caracteriza como un cúmulo de "pequeñas pavaditas" que, al mismo tiempo, constituyen "experiencias muy violentas". Al intentar reponer los hilos de esa narrativa entrecortada, nos dice: "María: por ejemplo, el acto del 25 de mayo, bueno, los intérpretes, nunca voy a hacer de dama antigua ¿por qué no voy a hacer de dama antigua? Sí, "no vas a hacer de dama antigua". Después entendés por qué."

Luego, añade:

María: iba a una escuela de monjas, yo me hacía una colita y me quedaba todo el rulaje así inflado y en la escuela me mandaban nota: "no, ella se tiene

\begin{tabular}{l|l} 
Revista RBBA & Revista Binacional Brasil Argentina
\end{tabular} 
que hacer una trenza". Entonces yo llegaba a mi casa y peleaba y decía: "mira, yo no me voy a hacer una trenza porque nadie va con trenza, o sea, te molesta algo que es mío".

Son estas "cosas sueltas", que ponen en evidencia la configuración de un capital racial negativo para aquellos sujetos socialmente considerados "no blancos", las que María ahora puede analizar desde otra perspectiva, en tanto forman parte de "otro relato". Sin embargo, manifiesta que "no hay un discurso instalado" sobre estas cuestiones en su familia: "María: a mí me sigue pasando con mi hermana que dice la frase "estamos como los negros", y yo le digo "no, si somos negros" y como que le sigue haciendo ruido. Sigue siendo un lugar difícil de encontrarse".

Al igual que Lucía, al indagar en los motivos por los cuales, a diferencia de los demás miembros de su familia, asumió una identidad "negra", María señala el contacto con la sociedad y cultura brasileras como un hecho fundamental:

María: lo cultural me sirvió a mí. El candombe, la danza afro... que sí, llegaron con una beca de posgrado, lo cual es loquísimo. También por cosas que me ocurrieron en ese viaje. Yo lo pienso como parte de una reflexión académica y subjetiva.

Estas consideraciones nos demuestran que "la imposibilidad de ser dicho", a la que aluden las mujeres afrosantafesinas en relación a la "marca racial" en sus relaciones familiares, está directamente relacionada con el modelo de formación nacional argentino, en tanto "matriz idiosincrática de producción y organización de la alteridad interior" (SEGATO, 2007, p. 29). Como procuramos evidenciar a lo largo de este trabajo, en nuestro país la idea del "crisol de razas" dio origen a la invisibilización generalizada de la memoria étnica, haciendo irrelevante la heterogeneidad constitutiva de la nación. De hecho, en Argentina no hay nombre para la raza (SEGATO, 2010): lo que es fácilmente identificable en otros países como una práctica racista, aquí tiende a ser encasillado en otras formas de discriminación.

A diferencia del modelo de nación proyectado por las elites decimonónicas en Argentina, como señala Segato (2007), el país vecino no anuló la posibilidad de pluralidad, disponibilizando un campo privilegiado para la subjetivación. En efecto, la autora afirma que, a pesar del intenso racismo, se produjo, en lo que se refiere a la cultura y a la representación dominante de nación, un modelo de múltiples interpenetraciones, generalmente descripto 
¿CÓMO SER NEGRO EN UN MUNDO SIN NEGROS? CATEGORÍAS RACIALES E IDENTIDADES POLÍTICAS ENTRE AFRODESCENDIENTES DE LA CIUDAD DE SANTA FE (ARGENTINA)

como sincrético. De este modo, operó como vía de re-ingreso de la cultura de la negritud en nuestro país.

Sin embargo, no se trata solamente de una cuestión de relatos. En efecto, las activistas nucleadas en la Casa sostienen que el problema racial en Argentina es más complejo que la connotación positiva o negativa que a una u otra forma de identificación se le asigna. En relación a ello, durante su discurso en una mesa redonda realizada en el año 2015 a propósito del "Día de los Afroargentinos de tronco colonial”, Mirta sostenía:

Mirta: podemos decir que en la actualidad las mujeres afro ocupamos los lugares que nos asignaron en aquellos momentos en que nos trajeron contra nuestra voluntad desde África; habitando los barrios más empobrecidos y en trabajos precarizados, lo que ahora llaman "trabajo en negro" (...) muchas de nuestras compañeras son "mucamas"; muchas cobran el plan "jefas de hogar"; y muchas de ellas son el blanco predilecto de esta "mantención de vagos" que supuestamente se hace con esos planes.

Por otra parte, durante su presentación en la 7ma Feria de Organizaciones Sociales realizada en 2016, afirmaba:

El acceso a la educación, a la buena salud, a la educación secundaria y terciaria de nuestros afrodescendientes también es negada. Y la discriminación en los boliches bailables, la persecución policial por portación de cara, eso también todavía lo seguimos sosteniendo.

A su vez, en ese mismo evento, Lucía manifestaba:

Lucía: Porque sí, estamos hablando de los africanos que vinieron y todo, pero ¿y los morochitos de las zonas marginales? Que no tienen acceso al estudio, por más que el estudio es gratuito, (...) no tienen trabajo digno, porque tampoco tienen la instrucción que les permita conseguir un trabajo que tenga una buena remuneración. Así que hay mucho por hacer.

En sus discursos observamos cómo las activistas nucleadas en la Casa procuran hilvanar los múltiples y contradictorios hilos que se tejen entre una marcación racial de negritud y la pertenencia a una posición de inferioridad en el orden socio-económico. Conexiones que, por otra parte, refieren a sus propias trayectorias de vida. En efecto, como mencionamos con anterioridad, la institución funciona en la casa de Lucía, ubicada en Santa Rosa de Lima, barrio con una alta cantidad de desocupados y/o beneficiarios de planes sociales, mujeres jefas de hogar, discapacitados, menores en diferentes situaciones de riesgo e innumerables problemáticas vinculadas a la marginalidad social (REYES y STUBBS, 2006). 
La infancia de Lucía fue en esa zona, que durante la segunda mitad del siglo XX albergó a familias obreras, en un contexto de transformaciones tendientes a la modernización del ejido urbano de la ciudad. De hecho, esta fue una de las principales razones por la cual fue elegida como una de las zonas para la realización de la prueba de captación de la población afrodescendiente en 2005. Muchos de los integrantes de la Casa son de estos barrios y, al no contar con estudios secundarios ni terciarios, en general, se desempeñan en trabajos precarizados.

\section{Conclusiones}

A lo largo de este trabajo procuramos dar cuenta de las estrategias utilizadas por un grupo de mujeres santafesinas para construir una identidad afrodescendiente. Para ello analizamos, por un lado, las prácticas y discursos públicos producidos por Lucía y Mirta, en tanto activistas afroargentinas nucleadas en la Casa de la Cultura Indo-Afro-Americana. Por otro lado, indagamos en sus experiencias de vida, así como en las de María, que, aunque se reivindica como mujer negra, no forma parte de la militancia política.

El análisis nos adentró en una problemática de larga data, relacionada con el modo en que las elites decimonónicas construyeron el ideal de nación argentina y los mecanismos a través de los cuales se pretendió homogeneizar a sus ciudadanos. Como señalamos en el primer apartado, el énfasis en la blanquedad de los argentinos, entendido como atributo de europeidad, tuvo un claro efecto performativo, conduciendo a los habitantes del país a pensarse efectivamente como blancos y europeos.

La reivindicación de la negritud en términos diaspóricos parecía no tener cabida en una sociedad que se imaginaba blanca, moderna y europea, pero por, sobre todo, en una sociedad en la que ser "negro" era un insulto. Sin embargo, el clima político-social inaugurado a partir de la década de 1980 ofrecería una estructura de oportunidades para el desarrollo de identidades en clave étnico-racial. Es en este contexto que Lucía Molina decide fundar la Casa, convirtiéndose en la primera institución del país en incursionar en el activismo político negro.

La adopción de una identidad política afrodescendiente, como evidenciamos en el segundo apartado, dio la posibilidad a las activistas afrosantafesinas de posicionarse personal 
SANTA FE (ARGENTINA)

y colectivamente de un modo inédito: como mujeres negras y argentinas, afirmando la heterogeneidad constitutiva de una nación que históricamente se jactó de ser la "más europea de las naciones latinoamericanas". En efecto, tanto Lucía como Mirta orientan sus esfuerzos a reconstruir una historia común, centrada en la reivindicación de la cultura de los afrodescendientes en la diáspora. En este sentido, se destaca la recreación y práctica de un candombe afro-litoraleño que, a pesar de no haber sido transmitido por generaciones precedentes, se incorpora en sus experiencias de vida como forma de establecer un reclamo político.

El tono de denuncia presente en los discursos de Lucía y Mirta nos recuerda que el reconocimiento de una historia afroargentina se torna valor como contra-discurso después de haber sido una narrativa secuestrada, abandonada por los mismos sujetos marcados racialmente como pre-requisito de acceso a la ciudadanía argentina. Y aún más, se torna valor como contra-discurso luego de que los mismos sujetos que hoy eligen identificarse como afrodescendientes se hayan sentido rechazados por ser más "oscuros" que el resto. Porque, aunque resulte paradójico, imaginarnos como una sociedad casi homogéneamente blanca no ha impedido la pervivencia de subrepticios mecanismos de discriminación racial.

Esto último queda expuesto al indagar en las trayectorias de vida de las mujeres afrosantafesinas recuperadas en este trabajo. Y se advierte en situaciones tan disímiles como las manifestadas por María en relación a los roles que puede desempeñar un niño en un acto escolar hasta el "derecho de admisión" en los boliches o la violencia policial ejercida por "portación de cara" señaladas por Mirta.

Sería un error caer en la simplificación de sostener que solamente los afrodescendientes son víctimas de estas experiencias de violencia, como también lo sería negar que el color de la piel continúa operando en la construcción de diferencias que se materializan en accesos diferenciados a bienes, servicios y oportunidades. A ello se enfrentan las mujeres que, si bien han elegido ser "negras" en un "mundo sin negros", han tenido que convivir con la marcación racial toda su vida. 


\section{Referencias}

BRIONES, C. Formaciones de alteridad: contextos globales, procesos nacionales y provinciales. En C. Briones (Ed.), Cartografías argentinas: políticas indígenas y formaciones provinciales de alteridad. Buenos Aires: Antropofagia, 2005.

BROGUET, J. Mujeres, negras y argentinas. Categorías identitarias entre mujeres afrodescendientes de la ciudad de Santa Fe (Argentina). Revista Estudios sobre las Culturas Contemporáneas, Colima, Vol. XXIII. Número 46, invierno 2017.

CIRIO, P. ¡Tomá pachuca! Historia y presente de los afroargentinismos. Buenos Aires: Teseo Press, 2015.

FRIGERIO, A. Y LAMBORGHINI, E. Los afroargentinos: formas de comunalización, creación de identidades colectivas y resistencia cultural y política. En R. Mercado y G. Catterberg (Ed.), Aportes para el desarrollo humano en Argentina: Afrodescendientes y africanos en Argentina. Buenos Aires: Programa Naciones Unidas para el Desarrollo, 2011.

GARCÍA, J. Comunidades afroamericanas y transformaciones sociales. En Estudios Latinoamericanos sobre cultura y transformaciones sociales en tiempos de globalización. Buenos Aires: CLACSO, 2001.

GELER, L. ¡Pobres negros! Algunos apuntes sobre la desaparición de los negros argentinos. En P. García Jordán (Ed.), Estado, región y poder local en América Latina, siglos XIX-XX: algunas miradas sobre el Estado, el poder y la participación política. Barcelona: Universitat de Barcelona, 2007.

GELER, L. Categorías raciales en Buenos Aires. Negritud, blanquitud, afrodescendencia y mestizaje en la blanca ciudad capital. Revista Runa №37, 2016.

JELIN, E. Los trabajos de la memoria. Madrid: Siglo XXI, 2001.

LÓPEZ, L. C. “¿Hay alguna persona en este hogar que sea Afrodescendiente?” Negociações e disputas políticas em torno das classificações étnicas na Argentina. Rio Grande do Sul: UFRGS, 2005.

LÓPEZ, M. L. Una historia a contramano de la oficial: Demetrio Acosta el Negro Arigós y la sociedad coral carnavalesca Negros Santafesinos. Santa Fe: Cámara de Diputados de la Provincia de Santa Fe, 2011.

RAITER, A. Y ZULLO, J. Lingüística y política. Buenos Aires: Biblos, 1999.

RESTREPO, E. Intervenciones en teoría cultural. Popayán: Universidad del Cauca, 2012. 
REYES, H. Y STUBBS, J. Más allá de los promedios: Afrodescendientes en América Latina. Buenos Aires: Universidad Nacional Tres de Febrero, 2006.

RIBEIRO, G. L. Tropicalismo e Europeísmo. Modos de representar o Brasil e a Argentina. Em A. Frigerio e G. L. Ribeiro (Ed.), Argentinos e Brasileiros. Encontros, imagens e estereótipos. Petrópolis, Brasil: Vozes, 2002.

RUFER, M. Silencio y secreto: mirada, raza y colonialidad en la Pampa argentina desde un estudio de caso. En E. J. Bejarano, M. A. Grebe, D. Grewe y N. Lobensteiner (Ed.), Movilizando etnicidad. Políticas de identidad en contienda en las Américas: pasado y presente. Madrid: Iberoamericana, 2013.

SEGATO, R. L. La nación y sus otros. Raza, etnicidad y diversidad religiosa en tiempos de políticas de la identidad. Buenos Aires: Prometeo, 2007.

\section{Fuentes consultadas}

Entrevista a Lucía Molina, Santa Fe, 22 de agosto de 2014.

Entrevista a María, Paraná, martes 9 de diciembre de 2014.

Lucía Molina en "Argentina, raíces afro: visibilidad, reconocimiento y derechos” (2014).

Lucía Molina y Mirta Alzugaray en la Mesa Redonda "El Federalismo de los Afroargentinos Ayer y Hoy", Santa Fe, 8 de mayo de 2015.

CCIAA, “Actividades por los 26 años de la Institución”, Santa Fe, 2014.

Lucía Molina y Mirta Alzugaray en la “7ma Feria de Organizaciones Sociales”, Santa Fe, 27 de octubre de 2016.

\section{Notas}

' Esto significa que todo lo producido en una sociedad adquiere una significación particular en función de esas referencias establecidas. En relación a Argentina, afirmamos que a partir de este discurso de nación se configuró una representación ideal de los argentinos que derivó en un proceso de invisibilización de todos aquellos sujetos "no blancos".

"Con "formaciones nacionales de alteridad" nos referimos a "representaciones hegemónicas de nación que producen realidades" (SEGATO, 2007, p. 29). En este sentido, como señala Segato (2007), el modelo argentino habría estado caracterizado por la existencia de un "patrullaje homogeneizador" por parte de las instituciones y el trabajo estratégico de una elite portuaria e ideológicamente eurocéntrica en el control del Estado para nacionalizar una nación percibida como amenazadoramente múltiple en pueblos.

iii El nombre "María" es ficticio y responde al objetivo de preservar lo más posible la intimidad de la entrevistada. A diferencia de ella, Lucía y Mirta construyen su identidad afrodescendiente desde la militancia, siendo integrantes activas de la Casa de la Cultura Indo-Afro-Americana. Teniendo en cuenta que parte de sus trayectorias personales son expuestas en acciones públicas decidimos utilizar sus nombres reales.

iv Cabe señalar que, teniendo en cuenta la categorización local, este grupo de mujeres serían percibidas como "negras" o, por lo menos, como "no blancas". 


\footnotetext{
v Como señala Michael Pollak (en JELIN, 2001, p. 40), las memorias oficiales son intentos más o menos conscientes de definir y reforzar sentimientos de pertenencia, que apuntan a mantener la cohesión social y a defender fronteras simbólicas. Como toda narrativa, son selectivas y expresan relaciones de poder.

vi El crisol, señala Segato (2007, p. 259), consume materiales y los funde en ligas cuyos componentes primarios se pierden, son sacrificados en la producción de otro diferente. El modelo de crisol habría dado origen a una situación de discriminación generalizada, en la que cualquier peculiaridad idiosincrática llama la atención, marcando una vigilancia difusa (patrullamiento) de todos sobre todos.

vii Ribeiro (2002) plantea el "europeísmo" como la matriz del modo de representar la colectividad de los argentinos: remite a una articulación compleja de factores históricos, sociológicos, económicos, políticos, culturales y demográficos, que hacen que Europa sea el gran y subyacente referente distintivo de la argentinidad. viii Briones (2005) utiliza la categoría de "etnicización" para dar cuenta de aquellas formas de marcación que, basándose en "divisiones en la cultura" en vez de "en la naturaleza", contemplan la desmarcación/invisibilización y - apostando a la modificabilidad de ciertas diferencias/marcas - prevén o promueven la posibilidad general de pase u ósmosis entre categorizaciones sociales con distinto grado de inclusividad.

ix En este sentido, coincidimos con Broguet (2017) al atender no tanto a lo que la configuración de estas identidades globales significa, sino a lo que el proceso posibilita, corriéndonos de una interpretación unidireccional que entiende las acciones de visibilización de los afroargentinos como respuesta automática a las demandas de organismos transnacionales.

" La Sociedad Coral Carnavalesca "Negros Santafesinos" fue una comparsa popular de la ciudad de Santa Fe. Estuvo vigente entre 1900 y 1950, participando ininterrumpidamente en los festejos de carnaval de la ciudad. Su fundador y principal referente, Demetrio Acosta, más conocido como el "negro Arigós" había nacido en el Barrio del Tambor de la ciudad de Paraná (nombre que refiere al arraigo de la práctica del candombe, relacionada con el predominio de población afrodescendiente en la zona), desarrollando allí su gusto por la música afro. López (2011) señala que "el Negro" Molina, amigo de Demetrio Acosta, había sido el conductor de los carros adornados para el carnaval, así como del tractor que llevaba la carroza de la reina, además de tocar el banjo y la guitarra.

${ }^{x i}$ En una entrevista realizada en el año 2016, Lucía afirmaba que dicha palabra pertenece al idioma Kimbundu (lengua que se habla en la región de Angola). Más allá de la veracidad de dicha afirmación, creemos que se trata de un "afro-argentinismo", en los términos señalados por Cirio (2015), en tanto resultado sui géneris de procesos de (re)apropiación y (re)significación operados en un contexto diferente al de la sociedad que le dio origen.
}

\section{Sobre o autor}

Francisco Sosa. Licenciado en Historia por la Universidad Nacional del Litoral. Miembro investigador del PICT 2017-3306 "Esclavitud y Abolición en Buenos Aires y Santa Fe: perspectivas comparadas sobre el proceso de erosión de la institución esclavista en las primeras décadas republicanas (1810-1853)", dirigido por Magdalena Candioti. Integrante del proyecto $\mathrm{CAI}+\mathrm{D}$ 2016 "Orden social, asociacionismo y movilización en el espacio santafesino", dirigido por José Larker. Es autor de publicaciones en el área de Historia de los Afrodescendientes en Argentina. Correo electrónico: fes_500@hotmail.com 
198 ¿CÓMO SER NEGRO EN UN MUNDO SIN NEGROS? CATEGORÍAS RACIALES E IDENTIDADES POLÍTICAS ENTRE AFRODESCENDIENTES DE LA CIUDAD DE SANTA FE (ARGENTINA)

Recebido: 05.06.18

Aprovado: 02.07 .18 